\title{
Perioperative Management of Morbidly Obese Patients during Major Abdominal Surgery
}

\author{
Byeong-Gon Na, M.D. ', Sang-Jae Park, M.D., Ph.D. ${ }^{2}$ \\ ${ }^{1}$ Division of Hepatobiliary Surgery and Liver Transplantation, Department of Surgery, Asan Medical Center, University of Ulsan College \\ of Medicine, Seoul, ${ }^{2}$ Center for Liver and Pancreatobiliary Cancer, National Cancer Center, Goyang, Korea
}

The population with obesity is seeing a steady increase globally. Obesity is known to be associated with morbidity and mortality after major abdominal surgery, and this correlation becomes more prominent in morbidly obese (MO) patients. Accordingly, adequate preoperative evaluation and preparation should be performed with an understanding of the pathophysiological changes associated with the MO. Precise surgery and adequate postoperative management are also mandatory to reduce complications and unplanned readmissions. However, adequate guidelines for the perioperative management of $\mathrm{MO}$ patients undergoing major abdominal surgery are lacking. We provide an overview of the pathophysiologic changes and practical guidelines on the perioperative management of major abdominal surgery in MO patients.

Keywords: Obesity; Preoperative care; Surgery

\section{INTRODUCTION}

Obesity has attained epidemic status, with at least 2.8 million deaths attributable to overweight or obesity annually. In 2014, more than 1.9 billion adults ( $\geq 18$ years of age) were overweight worldwide, while over 600 million were obese [1].

Body weight can be classified into different categories, ranging from underweight to morbidly obese $(\mathrm{MO})$, according to body mass index (BMI). BMI is calculated by dividing the total body weight (TBW) in kilograms by the square of the height in meters. $\mathrm{MO}$ patients have a $\mathrm{BMI} \geq 40 \mathrm{~kg} / \mathrm{m}^{2}$.

Obesity is a well-established risk factor for hypertension, cardiovascular diseases, diabetes, hyperlipidemia, osteoarthritis, and several cancers including colon, endometrium, breast, and ovary [2]. MO patients are at a higher risk of developing these co-morbidities. In surgical patients, obesity was associated with increased perioperative morbidity, and
MO was a risk factor for mortality [3].

We recently performed a pylorus-preserving pancreaticoduodenectomy (PPPD) in a 67-year-old man from Mongolia with recurrent ampulla of Vater (AoV) cancer and morbid obesity (height, $176 \mathrm{~cm}$; weight, $160 \mathrm{~kg}$; BMI, $51.7 \mathrm{~kg} / \mathrm{m}^{2}$ ). The patient initially underwent a trans-duodenal ampullectomy for localized AoV cancer at other hospital; however, local recurrence developed 8 months later. We believed that performing PPPD as a definite treatment right away should be risky because of his $\mathrm{MO}$. Therefore, we encouraged him to lose weight by diet control and exercise for 1 month (weight, $148.3 \mathrm{~kg} ; \mathrm{BMI}, 47.8 \mathrm{~kg} / \mathrm{m}^{2}$ ). We considered the proper perioperative management components such as ventilator care, optimal fluid or drug dose, a positioning bed on which the patient was able to be placed during surgery, and even a stretcher cart. These considerations were unfamiliar and difficult to us because such a severe obese patient with cancer was the first time in our institution. Nevertheless, we

Received December 16, 2021; Accepted December 22, 2021

Corresponding author: Sang-Jae Park

E-mail spark@ncc.re.kr (iD) ORCID https://orcid.org/0000-0001-5582-9420

This work was supported by the National Cancer Center, Research Institute, Republic of Korea (Grant numbers 1810864-2).

(c) (\$) This is an Open Access article distributed under the terms of the Creative Commons Attribution Non-Commercial License (http://creativecommons.org/licenses/ by-nc/4.0), which permits unrestricted non-commercial use, distribution, and reproduction in any medium, provided the original work is properly cited. 
performed the PPPD with careful dissection to avoid bleeding and transfusion, and the patient was discharged on the 31 st postoperative day without any serious complications. The patient is now doing well without any recurrence for 36 months (weight, $126.6 \mathrm{~kg}$; BMI, $40.8 \mathrm{~kg} / \mathrm{m}^{2}$ ). Because these $\mathrm{MO}$ patients are unaccustomed in clinical practice, herein, we provide the overview of the pathophysiologic changes and the guidelines of perioperative managements of major abdominal surgery in the MO patients.

\section{FUNCTIONAL AND PATHOPHYSIOLOGIC CHANGES IN MORBIDLY OBESE PATIENTS}

\section{Cardiovascular changes}

Obesity contributes to hemodynamic alterations predisposing to alterations in cardiac morphology and ventricular function, which increase the stroke volume and cardiac output (CO) but decrease systemic vascular resistance (SVR) [4,5]. Ultimately, obesity adversely affects the cardiovascular structure and leads to left ventricular hypertrophy (LVH) as well as left ventricular (LV) systolic and diastolic dysfunction. Furthermore, these changes worsen as the magnitude of obesity increases [6]. Previous studies demonstrated LV enlargement ( $40 \%$ of participants), left atrial enlargement (50\% of participants), and increased thickening of the LV wall (56\% of participants) in MO patients $[4,7]$. The prevalence of heart failure (HF) also likely increases in obese patients. The major reason for this is that increased $\mathrm{CO}$ attributed to the increased blood volume may lead to elevated filling pressures, which eventually cause adverse remodeling of both cardiac function and structure [8]. Moreover, increased CO may cause the right ventricular hypertrophy and enlargement, which may result in right ventricular failure [4]. Based on these mechanisms, weight reduction may benefit cardiac function, but limited data are available to support the effect of intentional weight loss in patients with HF [9].

\section{Respiratory changes}

Increased abdominal pressure may result from increased abdominal and visceral adipose tissue deposition [10]. For this reason, the chest capacity of the $\mathrm{MO}$ patient is reduced due to the diaphragm compressed cranially compared to a non-obese patient. Since pulmonary compliance decreases in $\mathrm{MO}$ patients, the functional residual capacity (FRC) also decreases while the work of breathing (WOB) increases. Moreover, oxygen consumption in $\mathrm{MO}$ patients is 1.5-times higher than that in non-obese patients; therefore, sufficient oxygenation could be more difficult in MO patients [11]. Obese patients can also produce excessive carbon dioxide because of increased oxygen consumption. Biring et al. [12] showed that $\mathrm{MO}$ was associated with reduced forced vital capacity (FVC) and forced expiratory volume in 1 second $\left(\mathrm{FEV}_{1}\right)$. In another study, the obese group (BMI, $39 \pm 6 \mathrm{~kg} / \mathrm{m}^{2}$ ) had a significantly lower mean maximal inspiratory pressure than the control group (BMI, 23 $\pm 3 \mathrm{~kg} / \mathrm{m}^{2}$ ) [13]. Therefore, these functional impairments are more likely to develop as rapid shallow breathing in the $\mathrm{MO}$ patient, resulting in respiratory failure. This typical pattern was also confirmed in previous studies involving obese patients $[14,15]$. Consequently, postoperative atelectasis frequently develops in $\mathrm{MO}$ patients.

Sleep-disordered breathing often occurs in an obese patient. This condition ranges from obstructive sleep apnea (OSA) to obesity hypoventilation syndrome (OHS). OSA correlates with the incidence of postoperative desaturation, respiratory failure, and cardiac events [16]. When it is confirmed preoperatively using polysomnography or overnight oximetry testing, proper treatment with continuous positive airway pressure (CPAP) can reduce the risk of complications [17]. In addition to these tests, the loud Snoring, Tiredness, Observed apnea, high blood Pressure (STOP)-Body mass index, Age, Neck circumference and Gender (BANG) score was validated for detecting OSA in obese surgical patients [18]. When OSA remains untreated, it may progress to OHS, which is defined as a state of combined obesity (BMI $\geq 30$ $\left.\mathrm{kg} / \mathrm{m}^{2}\right)$, daytime hypercapnia $\left(\mathrm{PaCO}_{2}>45 \mathrm{mmHg}\right.$ ), and disordered breathing during sleep (after the exclusion of other disorders that might cause alveolar hypoventilation) [19].

\section{Pharmacologic changes}

Obesity affects physiobiological factors such as plasma proteins, drug metabolizing enzymes, drug transporters, and blood flow that are known to determine drug absorption, distribution, metabolism, and excretion [20]. First, regarding absorption, the increased splanchnic blood flow in obese patients may enhance oral drug absorption [21]. However, few studies in obese patients reported increased oral drug absorption. Although $\mathrm{CO}$ increases in an obese patient, the blood flow rate per gram of fat tissue is significantly lower than that of a non-obese subject, which may delay the absorption of a subcutaneously administered drug [22]. Second, the distribution in an obese patient mostly relies on the drug's lipophilicity. Lipophilic drugs tend to distribute into fat tissue, whereas hydrophilic drugs distribute into lean body tissue [23]. Moreover, serum protein concentrations and drug-protein affinities can be affected by obesity. The plasma fraction of drugs binding to albumin is not altered in obesity [24], while that of drugs binding to $\alpha_{1}$-acid glycoprotein correlated with obesity can be affected [25]. Third, histopathologic changes in the liver (fibrosis, cirrhosis, fat infiltration) and alterations in cytochrome activity can be caused by obesity and may affect drug metabolizing enzymes [26,27]. Phase I cytochrome P450 (CYPs)-mediated drug metabolism (oxidation, reduction, hydrolysis) are usually increased or unchanged, while the metabolism of drugs through phase II reactions (glucuronidation, acetylation, methylation, and sulfation) is mostly increased in obesity [28]. Moreover, previous studies showed that plasma fatty acid could affect various nuclear receptors, transcription factors, and membrane compositions of the en- 
doplasmic reticulum (ER), leading to modulate the expression and catalytic function of CYPs [29]. Finally, obese patients have a higher creatinine clearance $(\mathrm{CrCl})$ than non-obese patients [30]. Bauer et al. [31] showed that the $\mathrm{CrCl}$ of vancomycin in $\mathrm{MO}$ patients increased with body weight. Increases in the number or size of nephrons and blood flow to the kidney were suggested as possible reasons [32]; however, the exact cause of the increased clearance is unknown. For these reasons, a "one size fits all" dosing strategy according to drug type in obese patients may cause problems such as antibiotic treatment failure; thus, the proper dose should be considered. Although the dose of cephalosporins commonly used in surgical prophylaxis remains controversial, the higher doses based on body weight and dose in the upper limit of the normal range seems adequate for obese patients [33]. Among the penicillins, piperacillin/tazobactam has been extensively used in patients undergoing hepatobiliary pancreatic surgery. High-dose prolonged piperacillin/tazobactam infusion (4.5 g every 8 hours) is suggested because of increased distribution and clearance in obese patients [33]. A consistent initial dosing of vancomycin in obese patients could be the loading dose to 20 25 mg per TBW and be adjusted according to therapeutic drug monitoring [34].

\section{Thromboembolism}

Obesity is a prothrombotic state that increases morbidity and mortality owing to the development of myocardial infarction, stroke, and venous thromboembolism (VTE) [35-37]. The risk of VTE increases progressively with BMI in obese women compared to their non-obese counterparts [35]. Among the myriad of metabolic abnormalities related to obesity, chronic inflammation and impaired fibrinolysis are considered responsible for obesity-induced thrombosis [38]. Therefore more intensive perioperative anti-thromboembolic management should be considered for the MO patients.

\section{PERIOPERATIVE MANAGEMENT}

\section{Preoperative management}

The importance of the perioperative evaluation and management of $\mathrm{MO}$ patients has been emphasized because of the increasing morbidity and mortality associated with functional status and comorbidities such as hypertension, diabetes, dyslipidemia, and cardiovascular disease [3,39]. For this reason, the preoperative evaluation should be preceded by a comprehensive history-taking, physical examination, assessment of functional capacity, and laboratory test to assess the surgical risk. Moreover, this process should be performed with a multidisciplinary approach consisting of surgeons, anesthesiologists, nurses, and other healthcare providers. The anesthesia assessment can be completed with the experienced anesthesiologist for intra- and postoperative management. Nurses perform the admission assessment for patient $\mathrm{BMI}$ and skin care. Other healthcare providers including dietitians/nutritionists and exercise program specialist assess the nutritional status and physical condition and educate the patients about healthy eating habits and patient-specific exercise. The MO patient's weight and calculated BMI should be followed regularly since it is helpful to adjust the operation date and ensure the suitable patient's gowns and types of equipment such as operation room bed, stretchers, and big and long operative instruments. It is necessary to arrange the additional personnel when positioning and transporting the patient to avoid accidents. It is beneficial to preoperatively estimate IBW, lean body weight, and adjusted body weight to help with calculations of medication doses and fluid amounts.

\section{1) Cardiovascular system}

Preoperative risk factors for coronary artery disease including diabetes, hypertension, dyslipidemia, inflammation, and a hypercoagulable state are fully evaluated. A patient's functional status can be deduced from his ability to perform daily activities because the increased cardiorespiratory fitness (established by metabolic equivalents [METs]) decreases the risk of major adverse cardiac events (MACEs) [40]. For patients with elevated cardiac risk and poor or unknown functional capacity, exercise testing and cardiac imaging are adequate assessment options [41]. However, under the weight limitations of diagnostic equipment, the American College of Surgeons National Surgical Quality Improvement Program (NSQIP) Risk Index, estimating cardiac risk, can identify patients at high risk of major cardiac complications [18]. Echocardiography could be necessary to detect the hypertrophic and dilated cardiomyopathy as well as valvular heart disease.

\section{2) Respiratory system}

All patients should stop smoking and use incentive spirometry before and after surgery. MO patients with confirmed or suspected OSA should initiate CPAP preoperatively to improve or optimize their perioperative physical status [42]. The observational study showed that the preoperative CPAP could contribute to a lower risk of severe postoperative complications (cardiac events, respiratory failure, urgent respiratory support) [43]. The airway, nasopharyngeal anatomy, neck circumference, and tongue volume should be examined for cases that involve difficult and failing intubation.

\section{3) Weight control}

The use of very-low-energy diets (VLED) is common in obese patients before bariatric surgery since it provides rapid weight loss without compromising immune function or wound healing [44-46]. A VLED includes the ingestion of 3 shakes/day of a commercial product formulating very-lowcalorie diet $(456 \mathrm{kcal})$ with $52 \mathrm{~g}$ protein, $7 \mathrm{~g}$ fat, and $45 \mathrm{~g}$ carbohydrate plus the recommended daily intake of vitamins, minerals, and trace elements for 12 weeks $[47,48]$. The intake of low-starch vegetables (up to $250 \mathrm{~g}$ ) and $\geq 2 \mathrm{~L}$ /day of 
water or other calorie-free beverages is encouraged to ensure that the total calorie intake ranges from $456 \sim 680 \mathrm{kcal} /$ day. Rapid weight loss reduces liver volume and facilitates access to the stomach and esophageal hiatus, thereby improving the technical ease of bariatric surgery $[48,49]$. This concept has been broadened into other surgical specialties, including other upper abdominal operations, colorectal surgery, and cardiac procedures [50]. However, this is not a consistent finding in the literature and requires further validation.

There is also extensive knowledge that exercise can improve cardiopulmonary function, physical fitness, and quality of life (QoL) [51]. Previous reviews reported that exercise could reduce patient weight by $1.5 \sim 3.5 \mathrm{~kg}[52,53]$. The exercise program for $\mathrm{MO}$ patients can include daily routine activities, such as brisk walking or cycling, walking a certain number of steps each day or climbing stairs. Although most studies appraising exercise intensity in obese patients described bariatric surgery, the effective exercise program for weight loss could be achieved with a median intensity of $65 \%$ of peak heart rate or the maximum rate of oxygen consumption $\left(\mathrm{VO}_{2 \max }\right)$ with at least partial supervision for a median of 12 weeks [54]. With preoperative diet and exercise, more than $5 \% \sim 10 \%$ of weight loss is recommended for $\mathrm{MO}$ patients waiting for major abdominal operation. However for cancer patients, 3 months interval may be harmful due to the possibility of disease progression. The optimal program for MO patients depends on the patient's physical ability and disease status.

\section{4) Antibiotic prophylaxis}

A 2-g dose of prophylactic cefazolin at the time of anesthesia induction has been suggested without adjustment for weight [55]. Due to insufficient high-level evidence, the optimal dosing of antibiotic-related prophylaxis in obese patients remains challenging.

\section{5) Thromboprophylaxis}

Patients with a history of deep vein thrombosis should undergo a diagnostic evaluation for it [41]. The use of a prophylactic vena cava filter may present a greater risk than benefit due to filter-related thrombosis [56]. Thus, prophylactic pharmaceuticals are the mainstay of preventing VTE in obese patients according to the following criteria: prolonged immobilization; total operation time $>90$ min; age > 60 years; BMI > $30 \mathrm{~kg} / \mathrm{m}^{2}$; cancer; dehydration; and a family history of VTE [56]. The American Society of Hematology guideline suggests dose selection of low molecular weight heparin (LMWH) based on TBW rather than a fixed maximum daily dose for obese patients [57].

\section{Intraoperative management}

Intraoperative considerations during major abdominal surgery for $\mathrm{MO}$ patients encompass proper positioning, intravenous or central line placement, monitoring, and pertinent anesthesia. Airway management, fluid administration, and the prevention of thrombotic complications, pressure sores, and peripheral nerve injuries remain challenging. Additionally, abdominal surgery for obese patients often leads to poor outcomes. In colorectal surgery, obesity can make it difficult to identify the surgical planes and increase the rate of conversion from minimally invasive to open surgery [58]. House et al. [59] showed that obese patients who underwent PPPD were more likely to have pancreatic fistula and wound infection than non-obese patients. Therefore, major abdominal surgery in $\mathrm{MO}$ patients is technically demanding.

\section{1) Induction of general anesthesia and preparation}

The patient should be placed in a ramping position with the tragus of the ear level with the sternum and the arms away from the chest to aid with oxygenation and ventilation. This position has been recommended as the default position during induction for $\mathrm{MO}$ patients owing to the improved view at laryngoscopy [60]. Experienced anesthesiologists are likely to prevent adverse events in these patients. Ideal body weight (IBW) should be used to determine endotracheal tube size and calculate the tidal volume during mechanical ventilation. The formula for calculating IBW is as follows: IBW $(\mathrm{kg})=$ height $(\mathrm{cm})-100$ for a man and height $(\mathrm{cm})-110$ for a woman [61]. In MO patients, the optimal tidal volume should be calculated by the IBW, not by current body weight to avoid airway trauma. Tidal volume for $\mathrm{MO}$ patients is $6 \sim 8$ $\mathrm{mL} / \mathrm{kg}$ IBW with a Positive end-expiratory pressure (PEEP of $10 \mathrm{cmH}_{2} \mathrm{O}$ to avoid atelectasis. PEEP and a recruitment maneuver can prevent intra- or postoperative atelectasis. Given an obese patient's decreased FRC, the PEEP can prevent alveolar collapse; however, it cannot recruit the collapsed alveoli. Consequently, it is better to assess PEEP from the initiation of ventilation [62]. As intravenous access is often difficult in $\mathrm{MO}$ patients, portable ultrasonography may be useful for locating peripheral veins. If peripheral vein access is impossible, central line placement should be considered. Gel pads should be placed on pressure points to prevent pressure sores and peripheral nerve palsy.

\section{2) Fluid therapy}

Estimating cardiac filling pressures by monitoring central venous pressure (CVP) and pulmonary capillary wedge pressure during fluid administration in surgeries has low sensitivity and specificity [63]. Functional parameters (pulse pressure variation, stroke volume variation [SVV]) derived from an arterial pressure waveform analysis are more sensitive and specific [64]. Jain and Dutta [65] attempted to utilize SVV as an infusion trigger for intraoperative fluid management in a MO patient undergoing bariatric surgery. Moreover, Corcoran et al. [66] showed that the total amount of liberally administered fluid was not key in determining perioperative outcomes, while the titrating fluid volume meeting the functional parameters, and goal-directed fluid therapy (GDT), ap- 
peared to play a pivotal role in reducing renal complications, pneumonia, time to the first bowel movement, and length of stay. Goal-directed monitoring can provide information about fluid responsiveness when the fluid bolus is administered for organ perfusion. GDT can prevent the fluid accumulation that results from excessive fluid [67]. As a result, intraoperative SVV monitoring may warrant GDT in MO patients. Also, transthoracic echocardiography seems more informative for intraoperative fluid management in MO patients [68].

\section{3) Operation technique}

During open major surgery for $\mathrm{MO}$ patients, a sufficient abdominal incision should be made to ensure an adequate surgical field. As bleeding from the adjacent fat tissue complicates the operation, meticulous dissection and hemostasis should be performed. At the same time, operations should be completed quickly and accurately because $\mathrm{MO}$ patients are vulnerable to developing pressure sores from long operations. Since all tissues may be friable owing to fat deposition, an iatrogenic injury is likely to occur. In cases of PPPD, a fatty pancreas with a high $\mathrm{BMI}$ is a predisposing factor for pancreatic fistula formation [69]. To prevent fistula formation, stent placement in the pancreatic duct, fibrin glue application, and the use of a somatostatin analog may be helpful; however, the evidence is insufficient. Wound closure with drainage could prevent wound dehiscence in $\mathrm{MO}$ patients.

\section{Postoperative management}

After major surgery, the patient can be transferred to the post-anesthesia care unit or intensive care unit for immediate postoperative full monitoring. If possible, a sitting or semisitting positioning is preferentially recommended. The $\mathrm{MO}$ patient should be carefully extubated since spontaneous breathing may be difficult immediately after major abdominal surgery. To facilitate breathing, chest physiotherapy and noninvasive respiratory support should be considered.

\section{1) Protective ventilation}

A recent study reported that obese patients are ventilated with too-high tidal volumes in the postoperative period [70]. In both obese (including $\mathrm{MO}$ ) and non-obese patients, the optimal tidal volume is $6 \sim 8 \mathrm{~mL} / \mathrm{kg}$ IBW with a PEEP of 10 $\mathrm{CmH}_{2} \mathrm{O}$ to avoid atelectasis. Several studies demonstrated that respiratory mechanics and alveolar recruitment were significantly improved by the monitoring of PEEP in obese patients [10]. However, it is necessary to assess the hypotensive effects of a high PEEP due to compromised venous drainage. In the supine position, positional flow limitations and air trapping may impede respiratory management in obese patients [71]. Mahul et al. [72] indicated that T-piece and pressure support ventilation plus $0 \mathrm{cmH}_{2} \mathrm{O}$ of PEEP as weaning tests can be applicable to predict post-extubation inspiratory effort and WOB. Following extubation, CPAP or non-invasive ventilation might apply to the patient, even those without obstructive apnea syndrome. Postoperative atelectasis may be more likely to develop in $\mathrm{MO}$ patients due to the diminished FRC, which worsens in the supine position $[12,14]$. And supplemental oxygen is usually necessary [14]. The patient may return to the ward when the respiratory rate is normal and there are no periods of hypopnea or apnea for at least 1 hour and the arterial oxygen saturation comparable to the preoperative value [73]. Early mobilization also can facilitate the rapid improvement of atelectasis in $\mathrm{MO}$ patients with the aid of healthcare providers.

\section{2) Fluid administration}

Postoperative fluid administration in $\mathrm{MO}$ patients can be based on IBW or TBW; however, this therapy has doubleedged implications. On the one hand, fluid restriction may result in acute tubular necrosis and organ dysfunction; on the other hand, excessive fluid may lead to postoperative complications such as pulmonary edema, hypertension, and an increased requirement and duration of ventilatory support despite improved organ perfusion [74,75]. A systematic review concluded that the liberal use of fluid causing a fluid overload state should be avoided in major surgery. Like an earlier mentioned intraoperative GDT, postoperative GDT could be tailored by the responsiveness of validated and objectively measurable variables, such as serum lactate, oxygen delivery index, and $\mathrm{CO}$ rather than conventional hemodynamic goals such as arterial blood pressure, urine output, or CVP. Close monitoring of these variables with adjustment for intravenous fluid administration may improve the tissue perfusion and decrease the complications.

\section{3) Thromboembolism}

Prophylactic regimens after major surgery mainly include sequential compression devices as well as LMWH. Mechanical prophylaxis could be used primarily for patients at high bleeding risk, and the use of aspirin alone for VTE chemoprophylaxis is not recommended [76]. Although strong evidence is lacking, extended chemoprophylaxis could be selected for patients at high risk of VTE after hospital discharge. A large cohort study for VTE after bariatric surgery demonstrated a $73 \%$ overall risk of VTE after hospital discharge [77]. This extended strategy should be decided based on individual risk factors at the time of discharge, including VTE or bleeding complications.

\section{LIMITATIONS}

This review has some limitations. Most papers cited here included studies of $\mathrm{MO}$ patients who underwent bariatric surgeries since those related to the perioperative management of $\mathrm{MO}$ patients undergoing major abdominal surgery are lacking. Moreover, we did not follow the systematic literature review methodologically. However, despite these limitations, this review can pave the way for future management 
protocols for major abdominal surgery for $\mathrm{MO}$ patients by reflecting those of bariatric surgery based on the perception of pathophysiological changes that occur in morbid obesity.

\section{CONCLUSION}

Morbid obesity often involves complicated comorbidities and physiological alterations. Perioperative careful considerations in detail and multidisciplinary managements are needed. The main cardiovascular change is LVH resulting in $\mathrm{HF}$, and the reduction of FRC and increase in WOB is principal in respiratory function. OSA is a common problem in MO patients, who should receive perioperative CPAP. Understanding the pharmacological differences between obese and non-obese patients aids in the determination of dosages of perioperative drugs such as antibiotics. Preoperative optimization to achieve $5 \% \sim 10 \%$ of weight loss with adequate diet and exercise is very important. The ramping position in airway management and protective ventilation with PEEP plus calculated TV based on IBW is mandatory. The perioperative GDT targeting functional parameters is supposed to be reliable for fluid administration. The administration of perioperative anticoagulant therapy using LMWH for preventing VTE is recommended in $\mathrm{MO}$ patients. Most important thing for the $\mathrm{MO}$ surgical patients is a meticulous dissection technique to avoid massive bleeding serious complication.

\section{AUTHOR CONTRIBUTIONS}

Conceptualization: SJP. Investigation: BGN. Methodology: BGN. Supervision: SJP. Writing - original draft: BGN. Writing - review \& editing: SJP.

\section{CONFLICTS OF INTEREST}

The authors of this manuscript have no conflicts of interest to disclose.

\section{ORCID}

Byeong-Gon Na, https://orcid.org/0000-0002-3150-4645

Sang-Jae Park, https://orcid.org/0000-0001-5582-9420

\section{REFERENCES}

1. Kelly T, Yang W, Chen CS, Reynolds K, He J. Global burden of obesity in 2005 and projections to 2030. Int J Obes (Lond) 2008;32:1431-7.

2. World Health Organization. Obesity and overweight [Internet]. Geneva: World Health Organization; 2017 [cited 2017 Oct 31]. Available from: http://www.who.int/mediacentre/factsheets/fs311/en/.

3. Bamgbade OA, Rutter TW, Nafiu OO, Dorje P. Postoperative complications in obese and nonobese patients. World J Surg 2007;31:556-60; discussion 561.
4. Lavie CJ, Alpert MA, Arena R, Mehra MR, Milani RV, Ventura HO. Impact of obesity and the obesity paradox on prevalence and prognosis in heart failure. JACC Heart Fail 2013;1:93-102.

5. Parto P, Lavie CJ. Obesity and cardiovascular diseases. Curr Probl Cardiol 2017;42:376-94.

6. Alpert MA, Omran J, Bostick BP. Effects of obesity on cardiovascular hemodynamics, cardiac morphology, and ventricular function. Curr Obes Rep 2016;5:424-34.

7. Patel DA, Lavie CJ, Milani RV, Gilliland Y, Shah S, Ventura HO. Association of left ventricular geometry with left atrial enlargement in patients with preserved ejection fraction. Congest Heart Fail 2012;18:4-8.

8. Alpert MA, Lavie CJ, Agrawal H, Aggarwal KB, Kumar SA. Obesity and heart failure: epidemiology, pathophysiology, clinical manifestations, and management. Transl Res 2014;164:345-56.

9. Hsuan CF, Huang CK, Lin JW, Lin LC, Lee TL, Tai CM, et al. The effect of surgical weight reduction on left ventricular structure and function in severe obesity. Obesity (Silver Spring) 2010;18:1188-93.

10. Pelosi P, Croci M, Ravagnan I, Vicardi P, Gattinoni L. Total respiratory system, lung, and chest wall mechanics in sedated-paralyzed postoperative morbidly obese patients. Chest 1996;109:144-51.

11. Kress JP, Pohlman AS, Alverdy J, Hall JB. The impact of morbid obesity on oxygen cost of breathing (VO(2RESP)) at rest. Am J Respir Crit Care Med 1999;160:883-6.

12. Biring MS, Lewis MI, Liu JT, Mohsenifar Z. Pulmonary physiologic changes of morbid obesity. Am J Med Sci 1999;318:293-7.

13. Chlif M, Keochkerian D, Choquet D, Vaidie A, Ahmaidi S. Effects of obesity on breathing pattern, ventilatory neural drive and mechanics. Respir Physiol Neurobiol 2009; 168:198-202.

14. Eichenberger A, Proietti S, Wicky S, Frascarolo P, Suter M, Spahn DR, et al. Morbid obesity and postoperative pulmonary atelectasis: an underestimated problem. Anesth Analg 2002;95:1788-92, table of contents.

15. Salome CM, King GG, Berend N. Physiology of obesity and effects on lung function. J Appl Physiol (1985) 2010;108: 206-11.

16. Mutter TC, Chateau D, Moffatt M, Ramsey C, Roos LL, Kryger M. A matched cohort study of postoperative outcomes in obstructive sleep apnea: could preoperative diagnosis and treatment prevent complications? Anesthesiology 2014;121:707-18.

17. Weingarten TN, Flores AS, McKenzie JA, Nguyen LT, Robinson WB, Kinney TM, et al. Obstructive sleep apnoea and perioperative complications in bariatric patients. Br J Anaesth $2011 ; 106: 131-9$.

18. Lee TH, Marcantonio ER, Mangione CM, Thomas EJ, Polanczyk CA, Cook EF, et al. Derivation and prospective validation of a simple index for prediction of cardiac risk of major noncardiac surgery. Circulation 1999;100:1043-9.

19. Pépin JL, Timsit JF, Tamisier R, Borel JC, Lévy P, Jaber S. Prevention and care of respiratory failure in obese patients. Lancet Respir Med 2016;4:407-18.

20. Jain R, Chung SM, Jain L, Khurana M, Lau SW, Lee JE, et 
al. Implications of obesity for drug therapy: limitations and challenges. Clin Pharmacol Ther 2011;90:77-89.

21. Adams JP, Murphy PG. Obesity in anaesthesia and intensive care. Br J Anaesth 2000;85:91-108.

22. Sanderink GJ, Le Liboux A, Jariwala N, Harding N, Ozoux ML, Shukla U, et al. The pharmacokinetics and pharmacodynamics of enoxaparin in obese volunteers. Clin Pharmacol Ther 2002;72:308-18.

23. Ritschel WA, Kaul S. Prediction of apparent volume of distribution in obesity. Methods Find Exp Clin Pharmacol 1986;8:239-47.

24. Benedek IH, Blouin RA, McNamara PJ. Serum protein binding and the role of increased alpha 1-acid glycoprotein in moderately obese male subjects. Br J Clin Pharmacol 1984;18:941-6.

25. Morita K, Yamaji A. Changes in the serum protein binding of vancomycin in patients with methicillin-resistant Staphylococcus aureus infection: the role of serum alpha 1-acid glycoprotein levels. Ther Drug Monit 1995;17:107-12.

26. Westphal JF, Jehl F, Vetter D. Pharmacological, toxicologic, and microbiological considerations in the choice of initial antibiotic therapy for serious infections in patients with cirrhosis of the liver. Clin Infect Dis 1994;18:324-35.

27. Hunt CM, Westerkam WR, Stave GM, Wilson JA. Hepatic cytochrome P-4503A (CYP3A) activity in the elderly. Mech Ageing Dev 1992;64:189-99.

28. Brill MJ, Diepstraten J, van Rongen A, van Kralingen S, van den Anker JN, Knibbe CA. Impact of obesity on drug metabolism and elimination in adults and children. Clin Pharmacokinet 2012;51:277-304.

29. Su GM, Sefton RM, Murray M. Down-regulation of rat hepatic microsomal cytochromes P-450 in microvesicular steatosis induced by orotic acid. J Pharmacol Exp Ther 1999;291:953-9.

30. Pai MP. Estimating the glomerular filtration rate in obese adult patients for drug dosing. Adv Chronic Kidney Dis 2010;17:e53-62.

31. Bauer LA, Black DJ, Lill JS. Vancomycin dosing in morbidly obese patients. Eur J Clin Pharmacol 1998;54:621-5.

32. Blouin RA, Bauer LA, Miller DD, Record KE, Griffen WO Jr. Vancomycin pharmacokinetics in normal and morbidly obese subjects. Antimicrob Agents Chemother 1982;21:575-80.

33. Meng L, Mui E, Holubar MK, Deresinski SC. Comprehensive guidance for antibiotic dosing in obese adults. Pharmacotherapy 2017;37:1415-31.

34. Vance-Bryan K, Guay DR, Gilliland SS, Rodvold KA, Rotschafer JC. Effect of obesity on vancomycin pharmacokinetic parameters as determined by using a Bayesian forecasting technique. Antimicrob Agents Chemother 1993;37:436-40.

35. Parkin L, Sweetland S, Balkwill A, Green J, Reeves G, Beral V; Million Women Study Collaborators. Body mass index, surgery, and risk of venous thromboembolism in middleaged women: a cohort study. Circulation 2012;125:1897904.

36. Yusuf S, Hawken S, Ounpuu S, Bautista L, Franzosi MG, Commerford P, et al.; INTERHEART Study Investigators. Obesity and the risk of myocardial infarction in 27,000 participants from 52 countries: a case-control study. Lancet 2005;366:1640-9.

37. Wolk R, Berger P, Lennon RJ, Brilakis ES, Somers VK. Body mass index: a risk factor for unstable angina and myocardial infarction in patients with angiographically confirmed coronary artery disease. Circulation 2003;108:2206-11.

38. Blokhin IO, Lentz SR. Mechanisms of thrombosis in obesity. Curr Opin Hematol 2013;20:437-44.

39. Davenport DL, Xenos ES, Hosokawa P, Radford J, Henderson WG, Endean ED. The influence of body mass index obesity status on vascular surgery 30-day morbidity and mortality. J Vasc Surg 2009;49:140-7, 147.e1; discussion 147.

40. Kokkinos PF, Faselis C, Myers J, Narayan P, Sui X, Zhang J, et al. Cardiorespiratory fitness and incidence of major adverse cardiovascular events in US veterans: a cohort study. Mayo Clin Proc 2017;92:39-48.

41. Mechanick JI, Youdim A, Jones DB, Garvey WT, Hurley DL, McMahon MM, et al. Clinical practice guidelines for the perioperative nutritional, metabolic, and nonsurgical support of the bariatric surgery patient--2013 update: cosponsored by American Association of Clinical Endocrinologists, The Obesity Society, and American Society for Metabolic \& Bariatric Surgery. Obesity (Silver Spring) 2013;21 Suppl 1:S1-27.

42. American Society of Anesthesiologists Task Force on Perioperative Management of patients with obstructive sleep apnea. Practice guidelines for the perioperative management of patients with obstructive sleep apnea: an updated report by the American Society of Anesthesiologists Task Force on Perioperative Management of patients with obstructive sleep apnea. Anesthesiology 2014;120:268-86.

43. Gupta RM, Parvizi J, Hanssen AD, Gay PC. Postoperative complications in patients with obstructive sleep apnea syndrome undergoing hip or knee replacement: a casecontrol study. Mayo Clin Proc 2001;76:897-905.

44. Martin LF, Tan TL, Holmes PA, Becker DA, Horn J, Bixler EO. Can morbidly obese patients safely lose weight preoperatively? Am J Surg 1995;169:245-53.

45. Nielsen LV, Nielsen MS, Schmidt JB, Pedersen SD, Sjödin A. Efficacy of a liquid low-energy formula diet in achieving preoperative target weight loss before bariatric surgery. J Nutr Sci 2016;5:e22.

46. Pekkarinen T, Mustajoki P. Use of very low-calorie diet in preoperative weight loss: efficacy and safety. Obes Res 1997;5:595-602.

47. Andersen T. Liver and gallbladder disease before and after very-low-calorie diets. Am J Clin Nutr 1992;56(1 Suppl):235S-9S.

48. Colles SL, Dixon JB, Marks P, Strauss BJ, O'Brien PE. Preoperative weight loss with a very-low-energy diet: quantitation of changes in liver and abdominal fat by serial imaging. Am J Clin Nutr 2006;84:304-11.

49. Fris RJ. Preoperative low energy diet diminishes liver size. Obes Surg 2004;14:1165-70.

50. Shin SH, Lee YJ, Heo YS, Park SD, Kwon SW, Woo SI, et al. Beneficial effects of bariatric surgery on cardiac structure and function in obesity. Obes Surg 2017;27:620-5.

51. Fried M, Hainer V, Basdevant A, Buchwald H, Deitel $M$, Finer $N$, et al. Interdisciplinary European guidelines on sur- 
gery of severe obesity. Obes Facts 2008;1:52-9.

52. Egberts K, Brown WA, Brennan L, O'Brien PE. Does exercise improve weight loss after bariatric surgery? A systematic review. Obes Surg 2012;22:335-41.

53. Shaw K, Gennat H, O'Rourke P, Del Mar C. Exercise for overweight or obesity. Cochrane Database Syst Rev 2006;(4):CD003817.

54. Pouwels S, Wit M, Teijink JA, Nienhuijs SW. Aspects of exercise before or after bariatric surgery: a systematic review. Obes Facts 2015;8:132-46.

55. Forse RA, Karam B, MacLean LD, Christou NV. Antibiotic prophylaxis for surgery in morbidly obese patients. Surgery 1989;106:750-6; discussion 756-7.

56. Rowland SP, Dharmarajah B, Moore HM, Lane TR, Cousins J, Ahmed AR, et al. Inferior vena cava filters for prevention of venous thromboembolism in obese patients undergoing bariatric surgery: a systematic review. Ann Surg 2015;261:35-45.

57. Witt DM, Nieuwlaat R, Clark NP, Ansell J, Holbrook A, Skov J, et al. American Society of Hematology 2018 guidelines for management of venous thromboembolism: optimal management of anticoagulation therapy. Blood Adv 2018;2:3257-91.

58. Xia X, Huang C, Jiang T, Cen G, Cao J, Huang K, et al. Is laparoscopic colorectal cancer surgery associated with an increased risk in obese patients? A retrospective study from China. World J Surg Oncol 2014;12:184.

59. House MG, Fong Y, Arnaoutakis DJ, Sharma R, Winston $C B$, Protic $M$, et al. Preoperative predictors for complications after pancreaticoduodenectomy: impact of BMI and body fat distribution. J Gastrointest Surg 2008;12:270-8.

60. Collins JS, Lemmens HJ, Brodsky JB, Brock-Utne JG, Levitan RM. Laryngoscopy and morbid obesity: a comparison of the "sniff" and "ramped" positions. Obes Surg 2004;14:1171-5.

61. De Jong A, Chanques G, Jaber S. Mechanical ventilation in obese ICU patients: from intubation to extubation. Crit Care 2017;21:63.

62. Talab HF, Zabani IA, Abdelrahman HS, Bukhari WL, Mamoun I, Ashour MA, et al. Intraoperative ventilatory strategies for prevention of pulmonary atelectasis in obese patients undergoing laparoscopic bariatric surgery. Anesth Analg 2009;109:1511-6.

63. Osman D, Ridel C, Ray P, Monnet X, Anguel N, Richard C, et al. Cardiac filling pressures are not appropriate to predict hemodynamic response to volume challenge. Crit Care Med 2007;35:64-8.

64. Pösö T, Kesek D, Aroch R, Winsö O. Morbid obesity and optimization of preoperative fluid therapy. Obes Surg 2013;23:1799-805.

65. Jain AK, Dutta A. Stroke volume variation as a guide to fluid administration in morbidly obese patients undergoing laparoscopic bariatric surgery. Obes Surg 2010;20:709-15.
66. Corcoran T, Rhodes JE, Clarke S, Myles PS, Ho KM. Perioperative fluid management strategies in major surgery: a stratified meta-analysis. Anesth Analg 2012;114:640-51.

67. Rehm M, Haller M, Orth V, Kreimeier U, Jacob M, Dressel $\mathrm{H}$, et al. Changes in blood volume and hematocrit during acute preoperative volume loading with $5 \%$ albumin or $6 \%$ hetastarch solutions in patients before radical hysterectomy. Anesthesiology 2001;95:849-56.

68. Pösö T, Winsö O, Aroch R, Kesek D. Perioperative fluid guidance with transthoracic echocardiography and pulsecontour device in morbidly obese patients. Obes Surg 2014;24:2117-25.

69. Rosso E, Casnedi S, Pessaux P, Oussoultzoglou E, Panaro F, Mahfud M, et al. The role of "fatty pancreas" and of BMI in the occurrence of pancreatic fistula after pancreaticoduodenectomy. J Gastrointest Surg 2009;13:1845-51.

70. Jaber S, Coisel Y, Chanques G, Futier E, Constantin JM, Michelet $\mathrm{P}$, et al. A multicentre observational study of intra-operative ventilatory management during general anaesthesia: tidal volumes and relation to body weight. Anaesthesia 2012;67:999-1008.

71. Lemyze M, Mallat J, Duhamel A, Pepy F, Gasan G, Barrailler $\mathrm{S}$, et al. Effects of sitting position and applied positive end-expiratory pressure on respiratory mechanics of critically ill obese patients receiving mechanical ventilation*. Crit Care Med 2013;41:2592-9.

72. Mahul M, Jung B, Galia F, Molinari N, de Jong A, Coisel $\mathrm{Y}$, et al. Spontaneous breathing trial and post-extubation work of breathing in morbidly obese critically ill patients. Crit Care 2016;20:346.

73. Members of the Working Party, Nightingale CE, Margarson MP, Shearer E, Redman JW, Lucas DN, et al; Association of Anaesthetists of Great Britain; Ireland Society for Obesity and Bariatric Anaesthesia. Peri-operative management of the obese surgical patient 2015: Association of Anaesthetists of Great Britain and Ireland Society for Obesity and Bariatric Anaesthesia. Anaesthesia 2015;70:859-76.

74. Arkiliç CF, Taguchi A, Sharma N, Ratnaraj J, Sessler DI, Read $\mathrm{TE}$, et al. Supplemental perioperative fluid administration increases tissue oxygen pressure. Surgery 2003;133:49-55.

75. Sear JW. Kidney dysfunction in the postoperative period. Br J Anaesth 2005;95:20-32.

76. Geerts WH, Bergqvist D, Pineo GF, Heit JA, Samama CM, Lassen MR, et al. Prevention of venous thromboembolism: American College of Chest Physicians EvidenceBased Clinical Practice Guidelines (8th Edition). Chest 2008;133(6 Suppl):381S-453S.

77. Winegar DA, Sherif B, Pate V, DeMaria EJ. Venous thromboembolism after bariatric surgery performed by Bariatric Surgery Center of Excellence Participants: analysis of the Bariatric Outcomes Longitudinal Database. Surg Obes Relat Dis $2011 ; 7: 181-8$. 